\title{
Effects of climate model radiation, humidity and wind estimates on hydrological simulations
}

\author{
I. Haddeland ${ }^{1,2}$, J. Heinke ${ }^{3}$, F. Voß ${ }^{4}$, S. Eisner ${ }^{4}$, C. Chen ${ }^{5}$, S. Hagemann ${ }^{5}$, and F. Ludwig ${ }^{2}$ \\ ${ }^{1}$ Norwegian Water Resources and Energy Directorate, Oslo, Norway \\ ${ }^{2}$ Wageningen University and Research Centre, Wageningen, The Netherlands \\ ${ }^{3}$ Potsdam Institute for Climate Research, Potsdam, Germany \\ ${ }^{4}$ University of Kassel, Kassel, Germany \\ ${ }^{5}$ Max Planck Institute for Meteorology, Hamburg, Germany
}

Correspondence to: I. Haddeland (ingjerd.haddeland@nve.no)

Received: 22 July 2011 - Published in Hydrol. Earth Syst. Sci. Discuss.: 22 August 2011

Revised: 18 January 2012 - Accepted: 24 January 2012 - Published: 2 February 2012

\begin{abstract}
Due to biases in the output of climate models, a bias correction is often needed to make the output suitable for use in hydrological simulations. In most cases only the temperature and precipitation values are bias corrected. However, often there are also biases in other variables such as radiation, humidity and wind speed. In this study we tested to what extent it is also needed to bias correct these variables. Responses to radiation, humidity and wind estimates from two climate models for four large-scale hydrological models are analysed. For the period 1971-2000 these hydrological simulations are compared to simulations using meteorological data based on observations and reanalysis; i.e. the baseline simulation. In both forcing datasets originating from climate models precipitation and temperature are bias corrected to the baseline forcing dataset. Hence, it is only effects of radiation, humidity and wind estimates that are tested here. The direct use of climate model outputs result in substantial different evapotranspiration and runoff estimates, when compared to the baseline simulations. A simple bias correction method is implemented and tested by rerunning the hydrological models using bias corrected radiation, humidity and wind values. The results indicate that bias correction can successfully be used to match the baseline simulations. Finally, historical (1971-2000) and future (20712100) model simulations resulting from using bias corrected forcings are compared to the results using non-bias corrected forcings. The relative changes in simulated evapotranspiration and runoff are relatively similar for the bias corrected
\end{abstract}

and non bias corrected hydrological projections, although the absolute evapotranspiration and runoff numbers are often very different. The simulated relative and absolute differences when using bias corrected and non bias corrected climate model radiation, humidity and wind values are, however, smaller than literature reported differences resulting from using bias corrected and non bias corrected climate model precipitation and temperature values.

\section{Introduction}

Climate change is likely to have a significant impact on the global hydrological cycle and water resources (Bates et al., 2008). Due to large uncertainties it is hard to give precise predictions about how the hydrological cycle will change and how this will affect water availability. The estimates of these effects depend heavily on the meteorological input data used in hydrological model simulations. The impact of climate change on the global terrestrial water cycle is usually studied by using the output of climate models as input for hydrological models (e.g. Hagemann et al., 2011). However, despite the recent progress in the development of global climate models (GCMs), the Intergovernmental Panel on Climate Change (IPCC) notes that GCMs still exhibit biases in their ability to simulate key features of the observed climate system (Randall et al., 2007). 
Hydrologic impact studies have shown that unless GCM output, especially precipitation, is corrected for biases, results from the hydrological simulation will be unrealistic and of limited use (e.g. Wood et al., 2004; Sharma et al., 2007). The main idea behind bias correction is to adjust climate model output so that the variables used as input to hydrologic simulations become more similar to observations. The bias correction method is normally developed using a control (historic) time period for which observations exist, and thereafter corrections are imposed on the climate model data for both control and projection periods. Bias correction of precipitation and temperature has traditionally been given most of the attention (e.g. Wood et al., 2004; Piani et al., 2010; Themeß1 et al., 2010). However, other forcing variables (e.g. radiation, humidity, wind speed) can have significant biases in climate models. These biases subsequently influence evapotranspiration, runoff, snow accumulation and melt in hydrological simulations, which were also noted by Hagemann et al. (2011). Climate model outputs other than precipitation and temperature have received moderate attention among hydrologists and in climate change impact studies. There is, however, a wide spread in the shortwave forcings reported for the models included in IPCC AR4 (Meehl et al., 2007), and Storelvmo et al. (2009) found that the different methods used to calculate cloud droplet number concentration from aerosol mass concentration is the main contributor to the spread. Wild and Liepert (2010) argued that inadequacies in the simulation of the surface radiation balance in climate models may contribute to the poor simulation of decadal variations in precipitation during the 20th century, and that improved knowledge of the surface radiation balance is key to our understanding of variations in the hydrological cycle. Sensitivity analyses using various datasets as input to hydrological models have shown that the resulting water fluxes are sensitive to radiation values, see e.g. Shi et al. (2010) and Nasonova et al. (2011); a result of evapotranspiration being highly dependent on the amount of available energy. Materia et al. (2010) concluded that, for the SSiB model, river flow is most sensitive to precipitation variability, but changes in radiative forcing affect discharge as well.

Sperna Weiland et al. (2010) looked at the spread in resulting discharge estimates before and after bias correcting GCM precipitation, temperature and inferred potential evaporation, and found that bias correction resulted in discharge estimates closer to the baseline simulations. However, isolated effects on hydrologic simulations caused by differences in climate model output other than precipitation and temperature have to our knowledge not been quantified before. Also, a study on the implications for hydrologic control and projection results before and after bias correction of these input variables has not previously been conducted. The objectives of this study are to analyse how biases in radiation, humidity and wind influence resulting water fluxes in hydrological model simulations, and to analyse the impact of bias correction of these variables on control and projection periods.

\section{Method}

\subsection{Forcing datasets}

The baseline forcing dataset used in this study is called the WATCH forcing data (WFD; Weedon et al., 2011). The WFD variables for the period 1958-2001 are taken from the ERA-40 reanalysis product of the European Centre for Medium Range Weather Forecasting (ECMWF) as described by Uppala et al. (2005). The one-degree ERA40 reanalysis product was interpolated to half-degree resolution on the Climate Research Unit of the University of East Anglia (CRU) land mask, adjusted for elevation changes where needed and bias-corrected using monthly observations. Diurnal air temperature was bias-corrected with CRU data (New et al., 1999, 2000; Mitchell and Jones, 2005). Shortwave downward radiation (SW) was corrected using CRU cloud cover fractions, having found the grid-point specific correlations between monthly average SW and ERA40 cloud fraction. SW was also adjusted for the effects of tropospheric and stratospheric aerosol loading. Precipitation was adjusted using both a wet-day correction from CRU and precipitation totals from the GPCCv4 full data product (Rudolf and Schneider, 2005; Schneider et al., 2008; Fuchs, 2008), and corrected for undercatch (snowfall and rainfall separately) based on Adam and Lettenmaier (2003). For detailed information on the baseline forcing data, see Weedon et al. (2011).

The climate data (WATCH Driving Data; WDD) are taken from the ECHAM and IPSL climate models, see Hagemann et al. (2011) for details. The time period is 1960-2100, and the same forcing variables as for WFD are available. WDD precipitation and temperature data are bias corrected to WFD (Piani et al., 2010). The other variables (short- and longwave radiation, specific humidity, and wind speed) are interpolated from the spatial resolution of the climate model to 0.5 degree spatial resolution by a combination of bilinear and inverse distance interpolation (Waszkewitz et al., 1996). Figure 1 shows mean annual values of downward short- and longwave radiation, total downward radiation, specific humidity and wind speed for the period 1971-2000 for WFD, and climate model anomalies. Precipitation and temperature values are not shown since these variables, because of the bias correction, are very close for all datasets. Shortwave radiation shows large differences among the datasets, especially in Sub Sahara, South East Asia and at northern latitudes. The ECHAM and IPSL shortwave radiation values in some areas have opposite deviations from the WFD values, e.g. at northern latitudes (Fig. 1a). The relative differences among the datasets are lower for longwave than for shortwave radiation (Fig. 1b), but also this variable shows differences e.g. in the tropics. Compared to the WFD values, the WDD longwave radiation anomalies are in many places opposite to those of the shortwave radiation anomalies. Total radiation, i.e. shortwave and longwave radiation combined, is an important measure in evapotranspiration calculations, 
a) Shortwave downward radiation
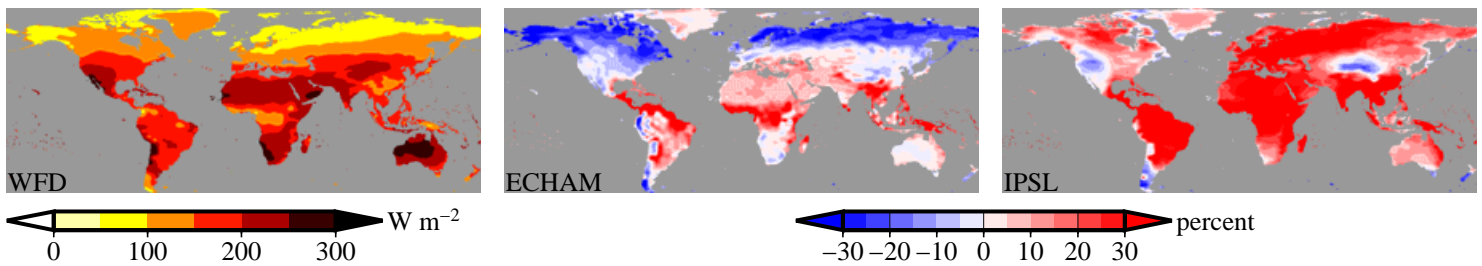

b) Longwave downward radiation
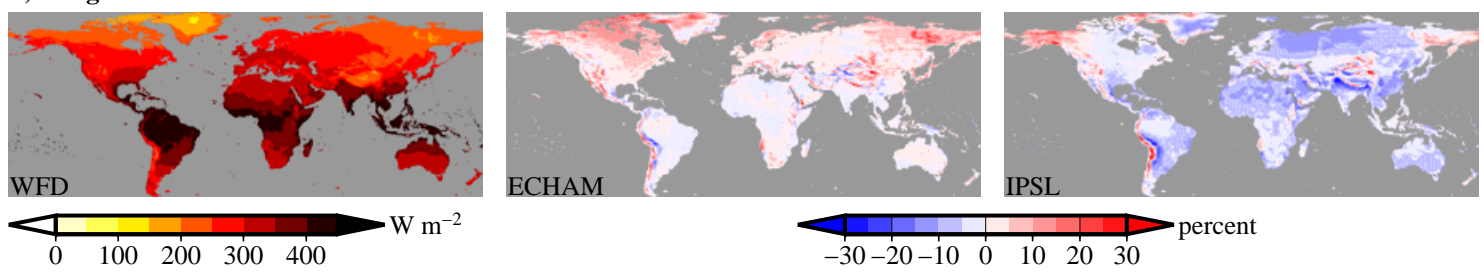

c) Total downward radiation
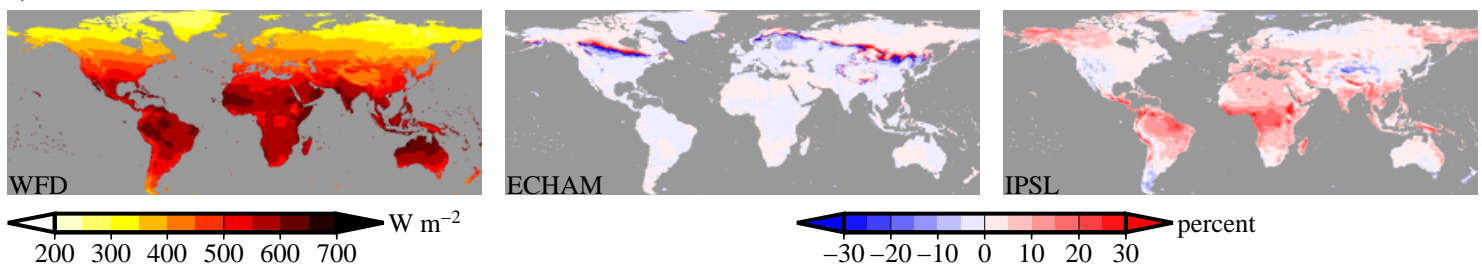

d) Specific humidity
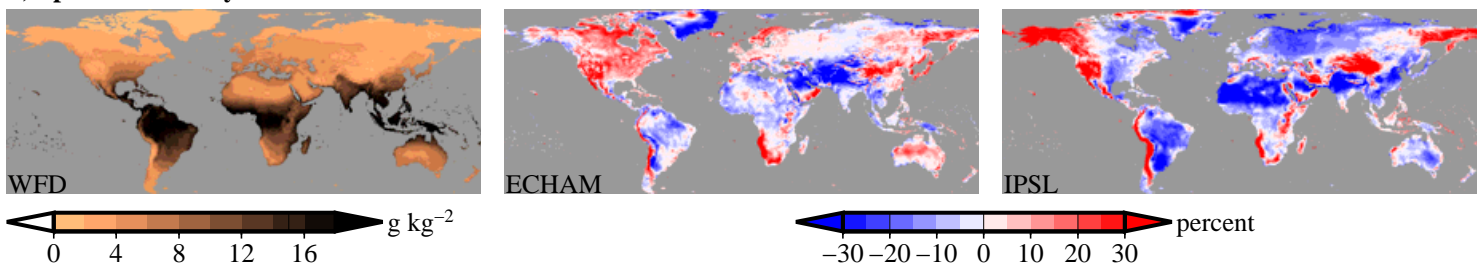

e) Wind
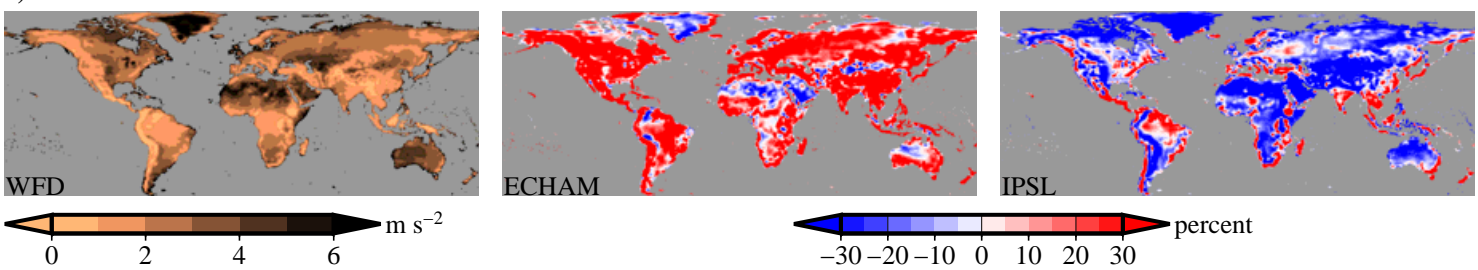

Fig. 1. Mean annual (1971-2000) WFD forcings and climate model anomalies. (a) Shortwave downward radiation, (b) longwave downward radiation, (c) Total downward radiation, (d) Specific humidity and (e) Wind speed.

and mean annual total downward radiation is also included in Fig. 1. The WDD specific humidity and wind speed values are both fairly different in all areas of the world compared to the WFD values (Fig. 1d and e).

\subsection{Hydrological models}

Four hydrological models participating in the EU WATCH project (Harding et al., 2011) are included in this study. The models, their main characteristics, and simulation results using historical forcing data are presented in Haddeland et al. (2011). In the present study, the main focus is on evapotranspiration and runoff estimates. The evapotranspiration schemes implemented in the models are reflected in what meteorological forcing variables are needed by the models, see also Table 1. MPI-HM makes use of the Thornthwaite evapotranspiration scheme, meaning the model only depends on precipitation and temperature. WaterGAP and LPJmL have implemented the Priestley-Taylor equation for evapotranspiration, and hence also depend on radiation values. VIC has implemented the Penman-Monteith equation for evapotranspiration and is additionally dependent, as direct input or internally estimated, on humidity and wind speed. 
Table 1. Participating hydrological models and input forcing datasets.

\begin{tabular}{|c|c|c|c|c|c|c|}
\hline \multirow[b]{2}{*}{$\begin{array}{l}\text { Model } \\
\text { name }\end{array}$} & \multirow[b]{2}{*}{ Reference(s) } & \multirow[b]{2}{*}{$\begin{array}{l}\text { Model } \\
\text { time } \\
\text { step }\end{array}$} & \multirow[b]{2}{*}{$\begin{array}{l}\text { Meteorological } \\
\text { forcing variables } 1\end{array}$} & \multicolumn{3}{|c|}{ Input forcing datasets and time periods included in analyses } \\
\hline & & & & $\begin{array}{l}\text { WFD } \\
\text { Baseline forcing } \\
\text { data } \\
1971-2000\end{array}$ & $\begin{array}{l}\text { WDD (ECHAM, } \\
\text { IPSL) } \\
\text { Bias corrected } \\
\text { precipitation and } \\
\text { temperature. } \\
\text { 1971-2000, } \\
2071-2100\end{array}$ & $\begin{array}{l}\text { ECHAM-BC, IPSL-BC } \\
\text { Bias corrected precipi- } \\
\text { tation, temperature, } \\
\text { short- and longwave } \\
\text { radiation, humidity and } \\
\text { wind speed. 1971-2000, } \\
2071-2100\end{array}$ \\
\hline LPJmL & $\begin{array}{l}\text { Bondeau et al. (2007), } \\
\text { Rost et al. (2008) }\end{array}$ & Daily & $P, T, \mathrm{SW}, \mathrm{LWn}$ & $\mathrm{X}$ & $\mathrm{X}$ & $\mathrm{X}$ \\
\hline MPI-HM & $\begin{array}{l}\text { Hagemann and Dümenil (1998), } \\
\text { Hagemann and Dümenil } \\
\text { Gates (2003) }\end{array}$ & Daily & $P, T$ & $\mathrm{X}$ & $\mathrm{X}$ & \\
\hline VIC & Liang et al. (1994) & Daily/3h & $\begin{array}{l}P, T_{\max }, T_{\min }, \mathrm{SW} \\
\mathrm{LW}, Q, W, \mathrm{SP}\end{array}$ & $\mathrm{X}$ & $\mathrm{X}$ & $X$ \\
\hline WaterGAP & Alcamo et al. (2003) & Daily & $P, T, \mathrm{SW}, \mathrm{LWn}$ & $\mathrm{X}$ & $\mathrm{X}$ & $\mathrm{X}$ \\
\hline
\end{tabular}

Precipitation, $T$ : air temperature, $T_{\max }$ : maximum daily air temperature, $T_{\min }$ : minimum daily air temperature, SW: shortwave radiation flux (downward), LW: longwave radiation flux (downward), LWn: longwave radiation flux (net), $Q$ : specific humidity, $W$ : wind speed, SP: surface pressure.

\subsection{Bias correction and hydrological model simulations}

Bias correction of climate model outputs for use in hydrological models, in particular precipitation and temperature, has often been performed based on the delta change method (e.g. Hay et al., 2000), or by a more sophisticated statistical bias correction method (e.g. Piani et al., 2010). Dynamical approaches, in which a regional climate model is nested within a general circulation model have also been used (e.g. Kim, 2001), as well as combinations of dynamical and statistical approaches (e.g. Wood et al., 2004). The bias correction performed on climate model precipitation and temperature prepared for WATCH was designed to adjust all moments of the probability distribution function of intensity for a specific variable, see Piani et al. (2010) for details. Hence, the original WDD precipitation and temperature data prepared for WATCH have been bias corrected to match the long-term statistics of WFD. However, the other variables included in WDD are raw climate model outputs. Despite the bias corrected precipitation and temperature values, the hydrological simulation results using WFD (Weedon et al., 2011) and WDD (Hagemann et al., 2011) for the LPJmL, VIC and WaterGAP models are quite different for the period 1971-2000.

The purposes of this study are to test whether a simple bias correction of forcing variables other than precipitation and temperature will yield more similar simulation results than before introducing the bias correction, and to analyze how it affects hydrologic projections. An underlying assumption is that the WFD forcing variables are closer to the true values than are the climate model outputs, although the method and analyses do not depend on this assumption. The bias correction was performed at daily time steps at the grid cell level as follows:

$$
V_{\mathrm{bc}}=V_{\mathrm{wdd}} * \frac{\bar{V}_{\mathrm{wfd}}(m)}{\bar{V}_{\mathrm{wdd}}(m)}
$$

where $V_{\mathrm{bc}}$ is the resulting bias corrected variable (shortwave radiation, longwave radiation, humidity or wind speed) for any given day, $V_{\mathrm{wdd}}$ is the original climate model output value, $V_{\text {wfd }}$ is the corresponding WFD variable, and $\bar{V}$ is the long-term mean monthly value for the variable and day in question. The long-term mean monthly relationships between WDD and WFD are hence used to correct the daily values in the climate model variables. The long-term mean differences in the period 1960-2000 are used for the entire period 1960-2100, and possible trends are not corrected. The use of monthly correction factors to correct for errors in climate model outputs is analogous to using the delta change approach (Hay et al., 2000). This method is identical to the method used by Sperna Weiland et al. (2010), although they performed the bias correction on inferred potential evaporation and not directly on climate model radiation, humidity and wind estimates. The LPJmL, VIC and WaterGAP models were rerun using the bias corrected variables as input forcings for the period 1960-2100 for the ECHAM and IPSL A2 projections. The MPI-HM model only makes use of temperature and precipitation data, and hence there was no need to rerun this model.

The hydrological models are run for the entire periods for which the forcing datasets are available, but in this paper only results for 1971-2000 (control period) and 20712100 (projection period) are presented. An overview of the forcing datasets used and the hydrological simulations performed is presented in Table 1. Analyses are carried out on mean annual global terrestrial evapotranspiration and runoff 


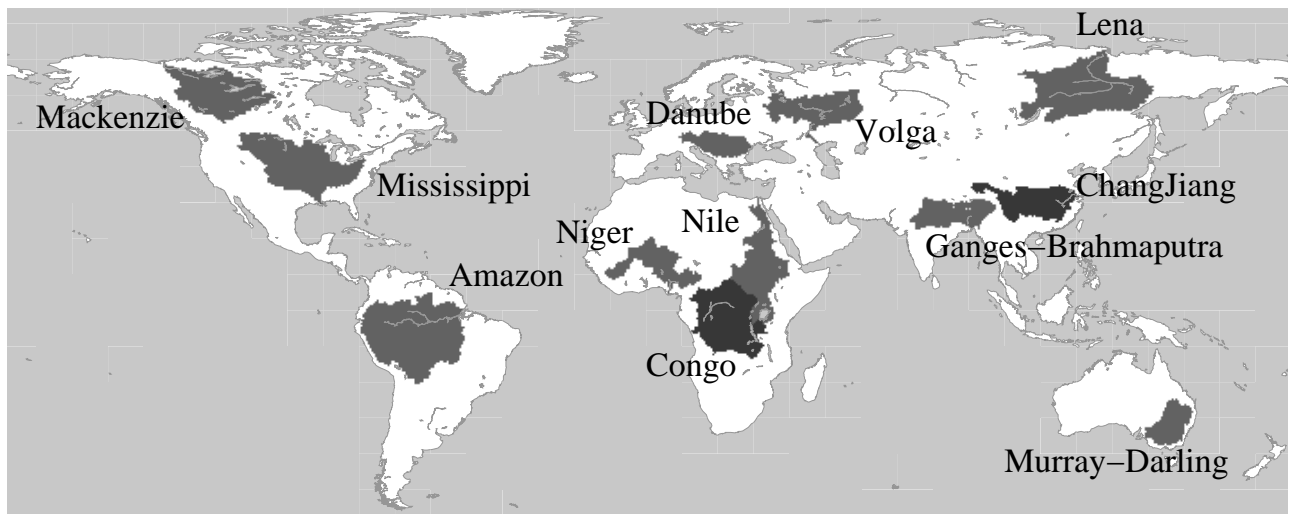

Fig. 2. Location of study basins.

a) LPJmL

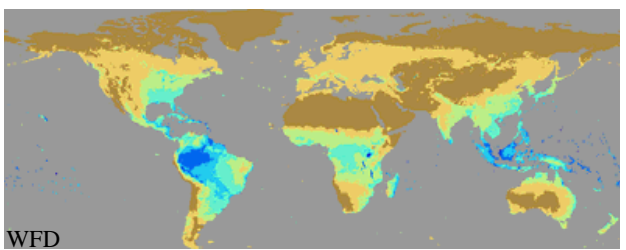

b) MPI-HM

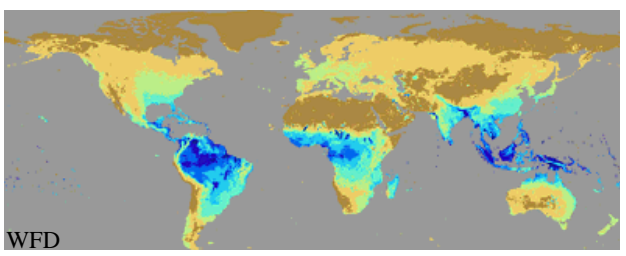

c) VIC

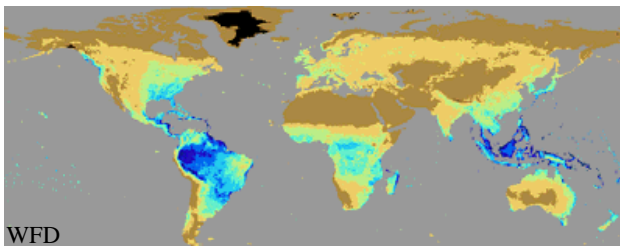

d) WaterGAP

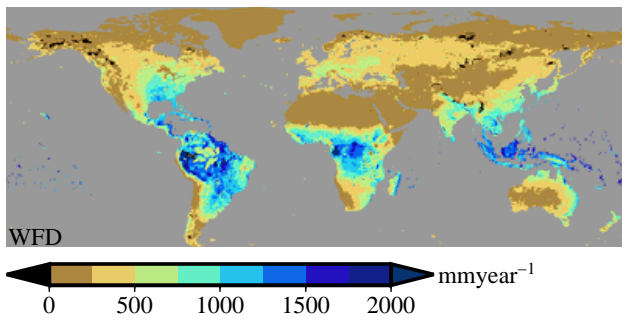

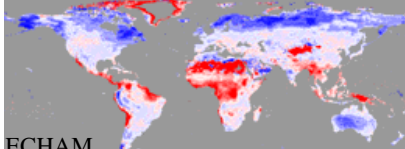
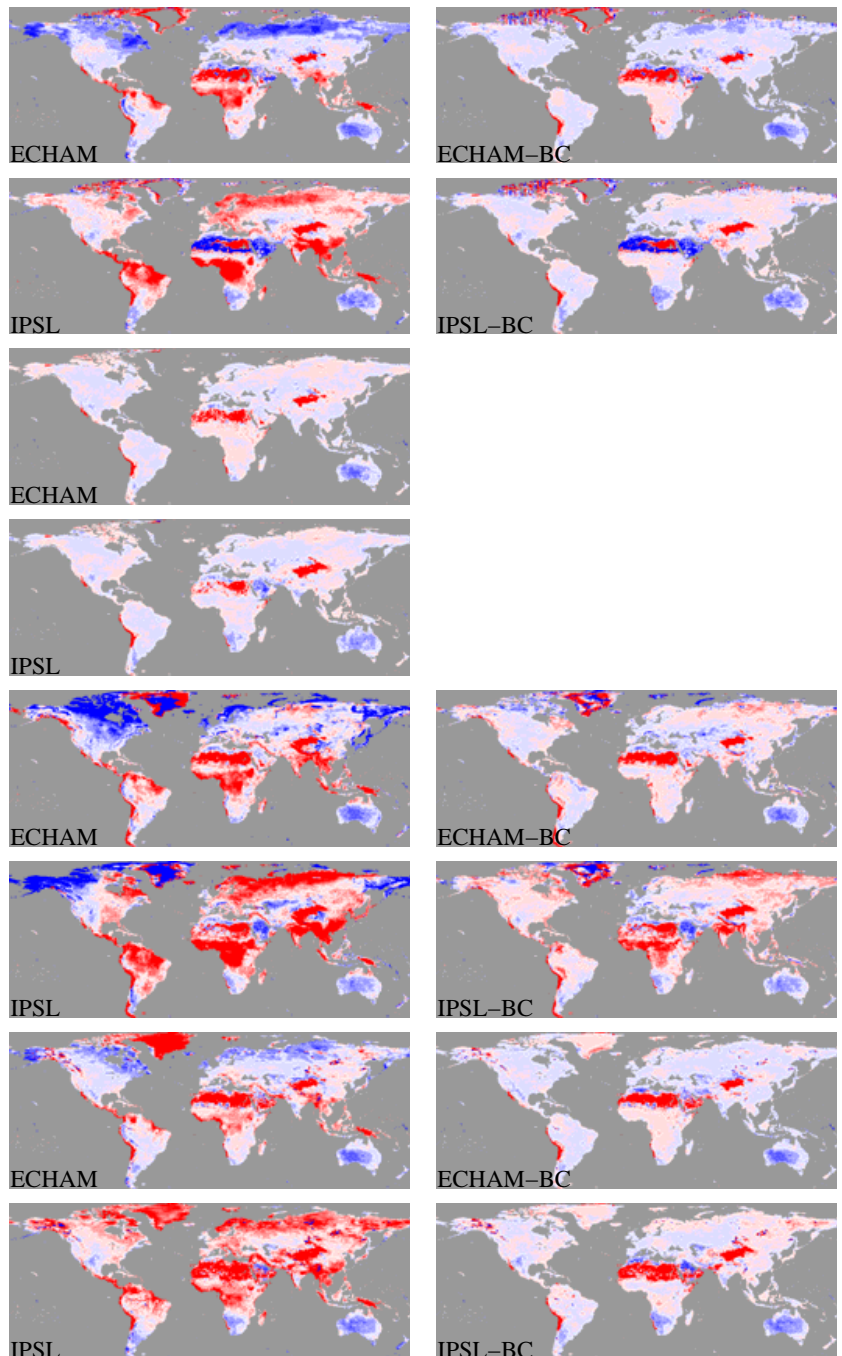

IPSL

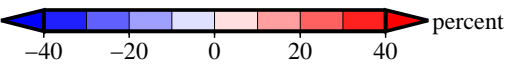

Fig. 3. Mean annual WFD evapotranspiration estimates for the (a) LPJmL, (b) MPI-HM, (c) VIC and (d) WaterGAP models, and WDD anomalies (original and bias corrected results when applicable). 


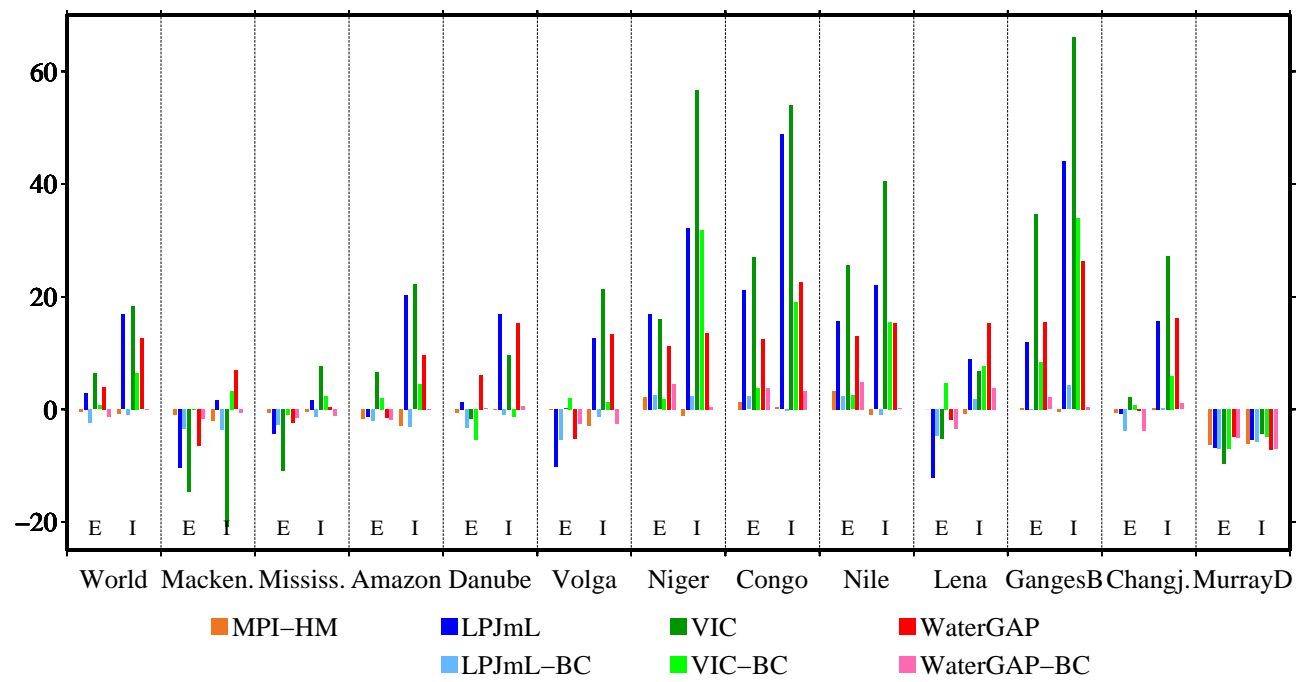

Fig. 4. Annual mean evapotranspiration differences (percent), with and without bias correction (BC) for the period 1971-2000 for the LPJmL, VIC and WaterGAP models when using WDD (ECHAM (E) and IPSL (I)), compared to the results using WFD. MPI-HM results using WDD, compared to the results using WFD, are included for reference purposes.

estimates, as well as mean monthly simulated evapotranspiration and runoff for some study basins; see location in Fig. 2 .

\section{Results and discussion}

\subsection{Hydrologic effects of forcing differences; original results and results after bias correction (1971-2000)}

Averaged over the period 1971-2000, mean annual simulated evapotranspiration is distinctly different when using WDD directly to force the hydrological models than when WFD is used, see Fig. 3. The evapotranspiration differences appear despite the bias correction that was originally performed on input precipitation and temperature values, and is evident in all model results except for the MPI-HM model. The MPI-HM model only makes use of precipitation and temperature as input meteorological data, and hence the results are fairly similar for all forcing datasets used in this study. Simulated evapotranspiration using original ECHAM forcings are closer to the WFD results than are the original IPSL simulated evapotranspiration, which might be expected when looking at differences in the input data (Fig. 1). However, even when using ECHAM forcings the annual differences in simulated evapotranspiration are fairly high e.g. at northern latitudes and parts of the tropics.

Figure 3 shows that simulated evapotranspiration for the LPJmL, VIC and WaterGAP models after bias correction of WDD radiation, humidity and wind speed are much closer to the baseline WFD results than before bias correction was introduced. In a few high-elevation areas (e.g. Himalaya) and some dry areas (e.g. Sahara and parts of Australia) the evapotranspiration differences are still more than 20 percent.
In these areas even the MPI-HM results are different, indicating that temporal differences in precipitation and temperature values at least partly explain the somewhat deviating results for the other models. The choice of evapotranspiration scheme and input forcing variables used clearly results in sensitivity differences to the climate model outputs, which is demonstrated by the results for all four models.

In Fig. 4, the spatially explicit results presented in Fig. 3 are averaged over the global terrestrial area and the study basins. The largest improvements can be found in the African basins (the Niger, Congo and Nile River basins), and in Asia (the Ganges-Brahmaputra and ChangJiang River basins). Annually averaged, the evapotranspiration match is closer after introducing the bias correction in the majority of the study basins. The difference is larger in a few basins, e.g. in the Lena basin using IPSL forcings in the WaterGAP model, and in the Danube River basin using ECHAM forcings for the LPJmL and VIC models. This is further discussed below.

Mean monthly (1971-2000) simulated evapotranspiration and runoff for a subset of the study basins before and after implementing the bias correction (Eq. 1) are presented in Figs. 5 and 6. The MPI-HM results are, again, fairly similar for all forcings used. However, also at the mean monthly level, the MPI-HM results indicate that differences in the precipitation and/or temperature characteristics cause slight differences in simulated water fluxes that are especially apparent when looking at runoff numbers (Fig. 6). Although precipitation and temperature are bias corrected, some differences in the correlation between the two variables before and after bias correction influence the results somewhat. The differences are hardly noticeable in the evapotranspiration estimates (Fig. 5), a result of the evapotranspiration numbers being higher than the runoff numbers and hence the relative 

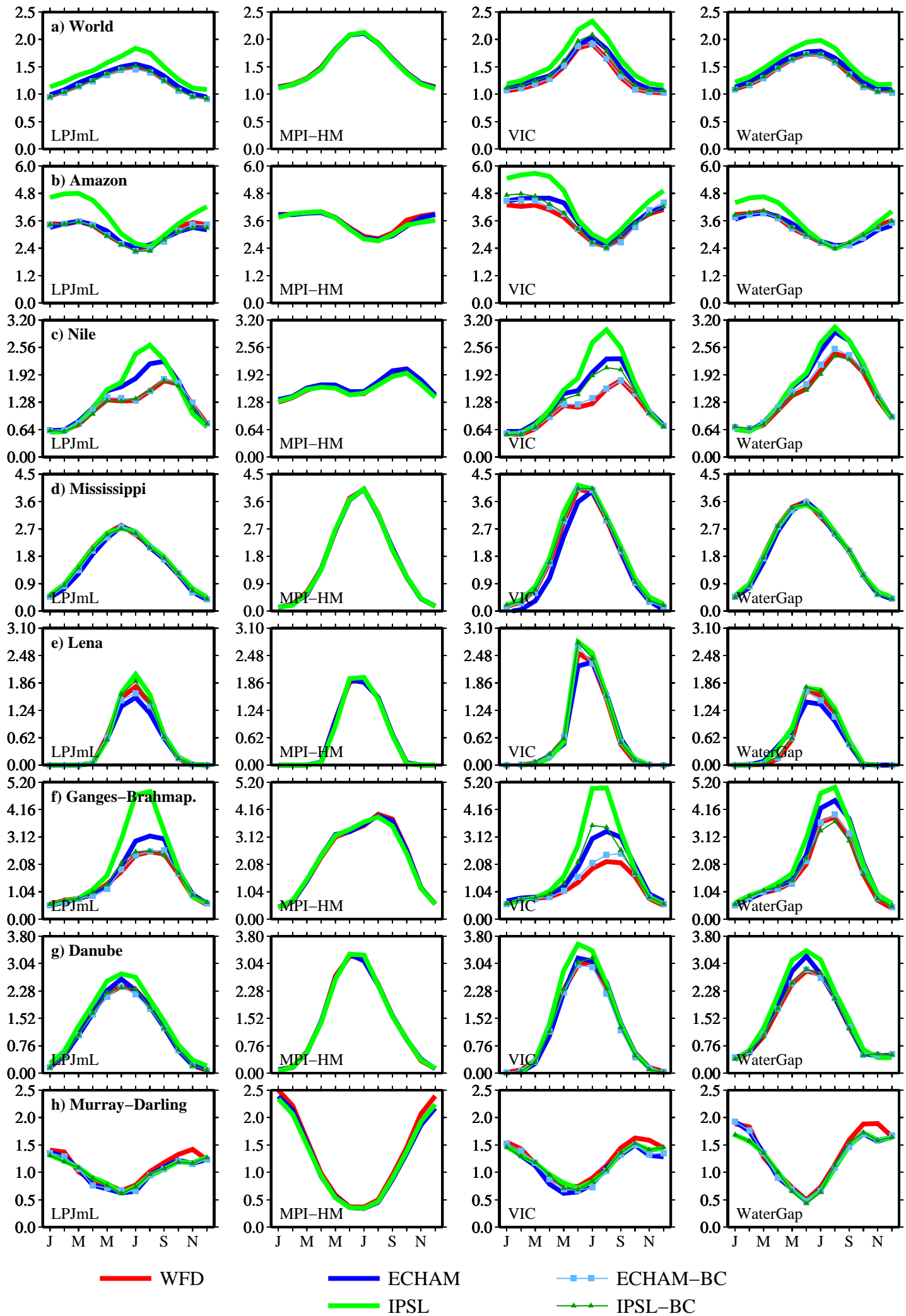

IPSL-BC

Fig. 5. Global terrestrial mean monthly simulated evapotranspiration $\left(\mathrm{mm} \mathrm{day}^{-1}\right)$, and results for the study basins (control period; 19712000). Original and bias corrected results when applicable. 
evapotranspiration differences are smaller than the relative runoff differences. Figure 5 also shows that the evapotranspiration match is favourable at the monthly scale after bias correction was introduced in the basins where the mean annual evapotranspiration deviations are slightly larger (Fig. 4), e.g. in the Danube (VIC, ECHAM) and Lena (WaterGAP, IPSL) River basins.

For the LPJmL, VIC and WaterGAP models, the basin results after bias correction of the input variables are much closer to the WFD results than when using the original climate model forcings. The most profound changes are seen for the Amazon, Nile and Ganges-Brahmaputra river basins, where the ECHAM results after bias correction almost perfectly match the WFD results. The IPSL bias corrected results for LPJmL and WaterGAP match the WFD results in most basins; also in the Amazon, Nile and GangesBrahmaputra basins. The bias corrected VIC IPSL results for the Nile and Ganges-Brahmaputra basins are much closer to the WFD results than before the bias correction, but do not perfectly match them. It is likely that variability of, and between, the input variables cause the match not to be perfect, and a bias correction method based on the long-term monthly deviations will not match the baseline forcing variables in all aspects. For the results presented here, this effect is more evident the more variables are used as input meteorological data. When calculating the correction factors and simulating for a shorter period (1985-1999), the VIC IPSL results (not shown) are closer to the WFD results than when the bias correction is performed over a $40 \mathrm{yr}$ time period. In the water limited Murray Darling river basin, the evapotranspiration differences are fairly small. However, for the VIC model differences appear in the runoff estimates, and the bias correction do not affect simulated runoff much. In this basin, monthly incoming radiation is similar in the climate models, and it is only humidity values that differ somewhat. The findings in Fig. 5 are similar to those of Sperna Weiland et al. (2010), although the Sperna Weiland et al. (2010) results also included the effects of bias correction on precipitation and temperature, and they used a slightly different bias correction approach (i.e. bias correction was performed on potential evaporation instead of directly on climate model outputs).

In the Ganges-Brahmaputra basin, the original IPSL evapotranspiration estimates are much higher than the ECHAM and WFD estimates during the Indian monsoon (Figs. 5 and 6). In this precipitation-rich period, total incoming radiation values are very different (not shown), mainly caused by lower shortwave radiation values in IPSL than in ECHAM and WFD. In general, it might be expected that radiation differences cause larger evapotranspiration differences in energy limited areas than in water limited areas. In order to investigate this issue further, the evapotranspiration fraction (here defined as mean annual evapotranspiration divided by mean annual precipitation) was used as a proxy for energy limitation, and differences in the originally simulated evapotran- spiration values were compared for the cells in the model domain where total incoming radiation is more than 10 percent higher in the climate model output than in WFD (see also Fig. 1c). The results are presented in Fig. 7, and shows that the models' sensitivity to differences in radiation is higher in areas with low evapotranspiration fractions than in areas with high evapotranspiration fractions. Hence, radiation differences in the forcing data have relatively larger effects on water fluxes in energy limited areas than in water limited areas. It should be noted, though, that small differences in water limited areas may be of higher societal and environmental importance than the larger differences in water rich areas.

\subsection{Hydrological projections with and without bias correction (2071-2100 compared to 1971-2000)}

Hagemann et al. (2011) showed that bias correction of precipitation and temperature can influence projected runoff changes profoundly (see e.g. Fig. 8 in Hagemann et al., 2011). A logical question for the study presented here is hence whether bias correction of radiation, humidity and wind speed influence projected changes in water fluxes. In order to answer this question, simulated runoff for the LPJmL, VIC and WaterGAP models with and without bias corrected forcings for the period 2071-2100 (projection period) are compared to simulated runoff for the period 1971-2000 (control period).

The mean annual relative runoff changes for the original and bias corrected simulations look similar in most areas of the world (Fig. 8; left and middle panels), when comparing simulated runoff for one climate model and one hydrological model. In Fig. 8 (right panels), the areas where the differences in the relative runoff changes are both (1) significant at the 5 percent level and (2) more than 5 percentage points are also shown. These areas cover 0.14 to $0.26 \times 10^{8} \mathrm{~km}^{2}$ for LPJmL ECHAM and IPSL results, 0.45 to $0.55 \times 10^{8} \mathrm{~km}^{2}$ for the VIC ECHAM and IPSL results, and 0.25 to $0.44 \times 10^{8} \mathrm{~km}^{2}$ for the WaterGAP ECHAM and IPSL results. This represents between 10 and 38 percent of the global terrestrial area (equalling $1.46 \times 10^{8} \mathrm{~km}^{2}$ for the land mask used in this study). Globally averaged, the projected changes without and with bias corrected climate forcings are presented in Table 2 and the leftmost part of Fig. 9. The bias correction of radiation, humidity and wind speed does not change the future relative predictions much at the global mean annual time scale, compared to using raw climate model outputs. However, as expected the absolute runoff values for both the control and projection period results are considerably different. Evapotranspiration is dependent on both forcing data and water availability; see also discussion related to Fig. 7. Hence, although it is not entirely surprising that the bias correction only has small impacts on the relative predictions, it is not obvious given that the evapotranspiration and runoff values are much altered. Table 2 also shows that there is a large spread in simulated water fluxes 

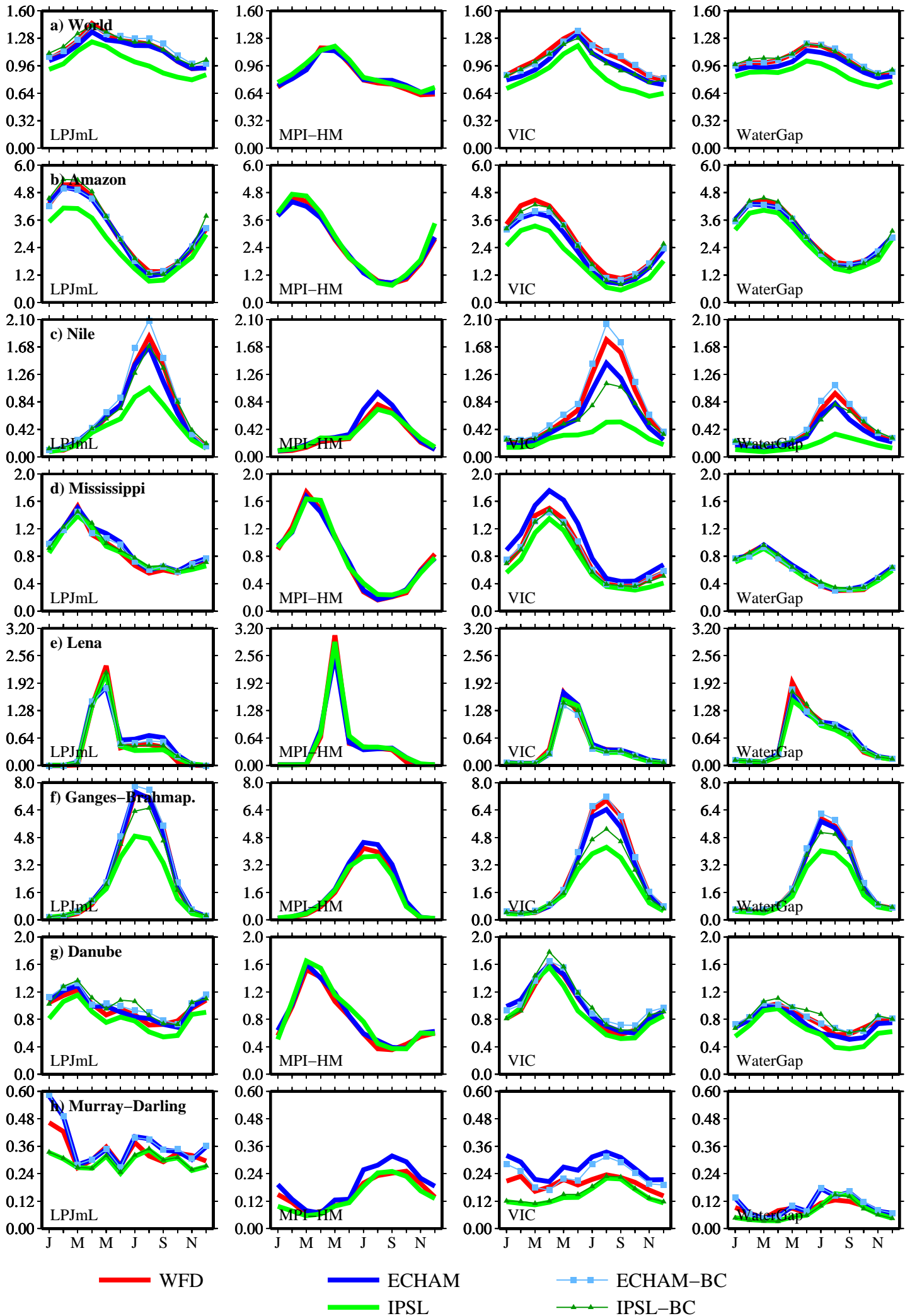

$\longrightarrow-$ ECHAM-BC
$\longrightarrow$ IPSL-BC

Fig. 6. Global terrestrial mean monthly simulated runoff $\left(\mathrm{mm} \mathrm{day}^{-1}\right)$, and results for the study basins (control period; 1971-2000). Original and bias corrected results when applicable. 

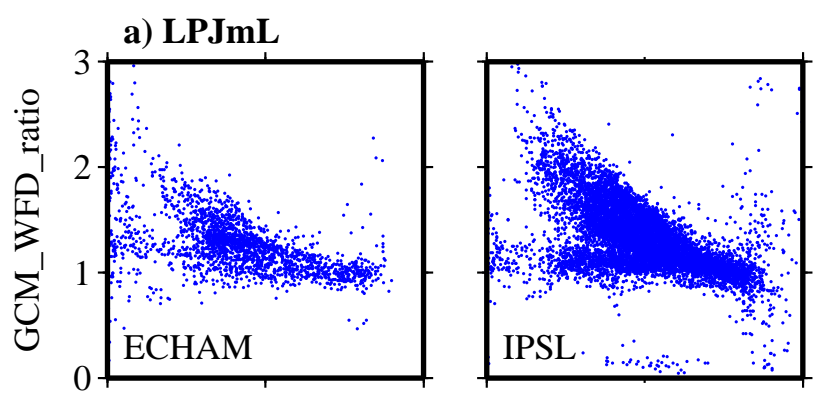

b) VIC
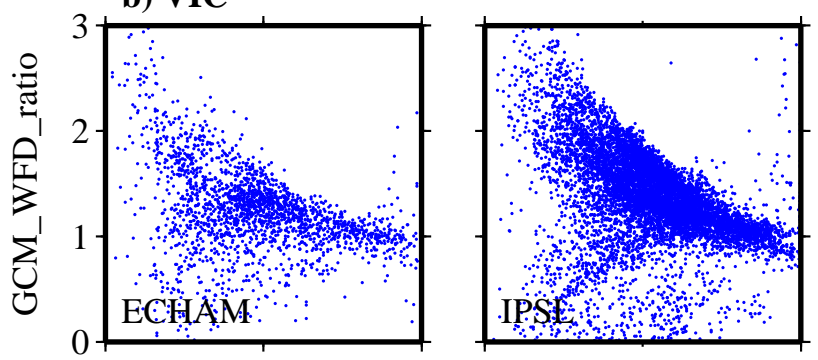

c) WaterGAP
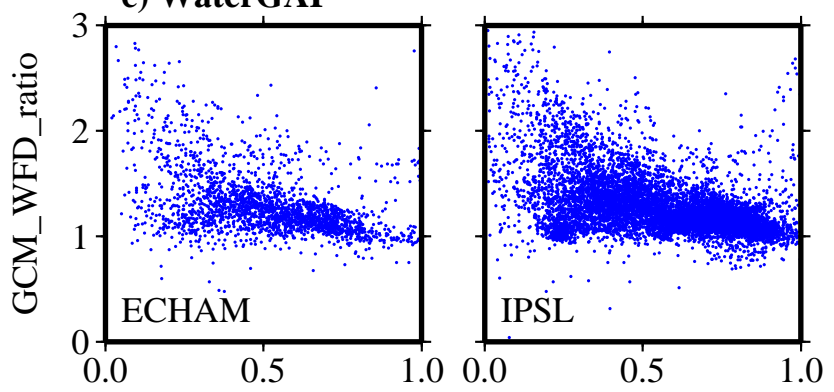

ET_fraction

ET_fraction

Fig. 7. WDD evapotranspiration fraction divided by WFD evapotranspiration fraction (y-axis) plotted against the WFD evapotranspiration fraction (original results, control period, ECHAM to the left, IPSL to the right). Only cells where the climate model total radiation is more than 10 percent higher than the WFD total radiation are included.

among the models; for more information on this topic see Haddeland et al. (2011) and Hagemann et al. (2011). Globally, the relative increase in runoff is slightly lower after introducing the bias correction; this is true for both climate model outputs and all hydrological models for which results can be compared (Table 2).

In the study basins, the effect of the bias correction on the hydrologic projections is in the order of a few percentage points, see Fig. 9. Although MPI-HM is not rerun using the bias corrected climate model forcings, the results of MPI-HM are included in Fig. 9 for reference purposes. Figure 9 shows that in most basins, the direction of the change of the projection signal is fairly consistent among the models, although the magnitude is somewhat different. Figure 9 also shows that the hydrologic projections using the MPI-
HM model in several basins are fairly different from the projections using the other three models; possible reasons for this are discussed in Hagemann et al. (2011). When comparing Fig. 9 to the results presented in Hagemann et al. (2011; Fig. 8), it appears that the effect of the bias correction of precipitation and temperature is higher than the effect of the bias correction of radiation, humidity and wind values. In the Hagemann et al. (2011) results, the differences in runoff projections before and after bias correction of precipitation and temperature in many basins are over five percent, and in some basins up to 20 percent. In this study, the differences are less than five percent for most basins and models. The study of Materia et al. (2010) and the Hagemann et al. (2011) study in combination with the study presented here, have somewhat different focus and should not be compared directly, but they both indicate that precipitation variation influence runoff more than radiation variations do.

The cumulative distribution functions based on basin averaged monthly runoff values for the LPJmL, VIC and WaterGAP models using IPSL input data for the periods 19712000 and 2071-2100 presented in Fig. 10 show that for both periods, the absolute numbers can be very different with and without bias correction. Only some of the study basins are included in Fig. 10, but the results in these basins illustrate the general model performance well. In most basins the relative change (projection period compared to control period) in simulated runoff is not much different whether the bias correction is employed or not. Hence, the introduction of a bias correction does not change the predicted signal of the future changes much. Among the basins included in Fig. 10, it is only for the VIC model in the Nile River basin the relative changes are clearly different in all parts of the distribution function. There are, however, some basins not included in Fig. 10 where the projected changes do deviate, e.g. in the African basins Niger and Congo, in the European basin Volga, and in the Mackenzie River basins in North America. Again, the largest deviations are found for the VIC model, but at the lower ends differences exist also for LPJmL in the Volga River basin (IPSL). Figure 10 clearly illustrates that the consequences of using raw climate model output in hydrological simulations, as compared to using bias corrected climate model output, are higher if simulated water fluxes are to be compared to absolute values (e.g. water requirements) than if the focus is on relative changes in water fluxes.

As mentioned in Sect. 2.3, correction factors calculated from the long-term historical relationship (1960-2000) are used for the entire simulation period (1960-2100). This implies the assumption that the mean bias of the model does not change with time, and possible historical and future trends in the correction functions are neglected. Depending on the climate model's ability to represent physical processes in the climate system, the relationship between modelled and observed values might be different at the end of the century than today. Also, climate models tend to underestimate variations in surface radiation compared to measurements (Wild, 

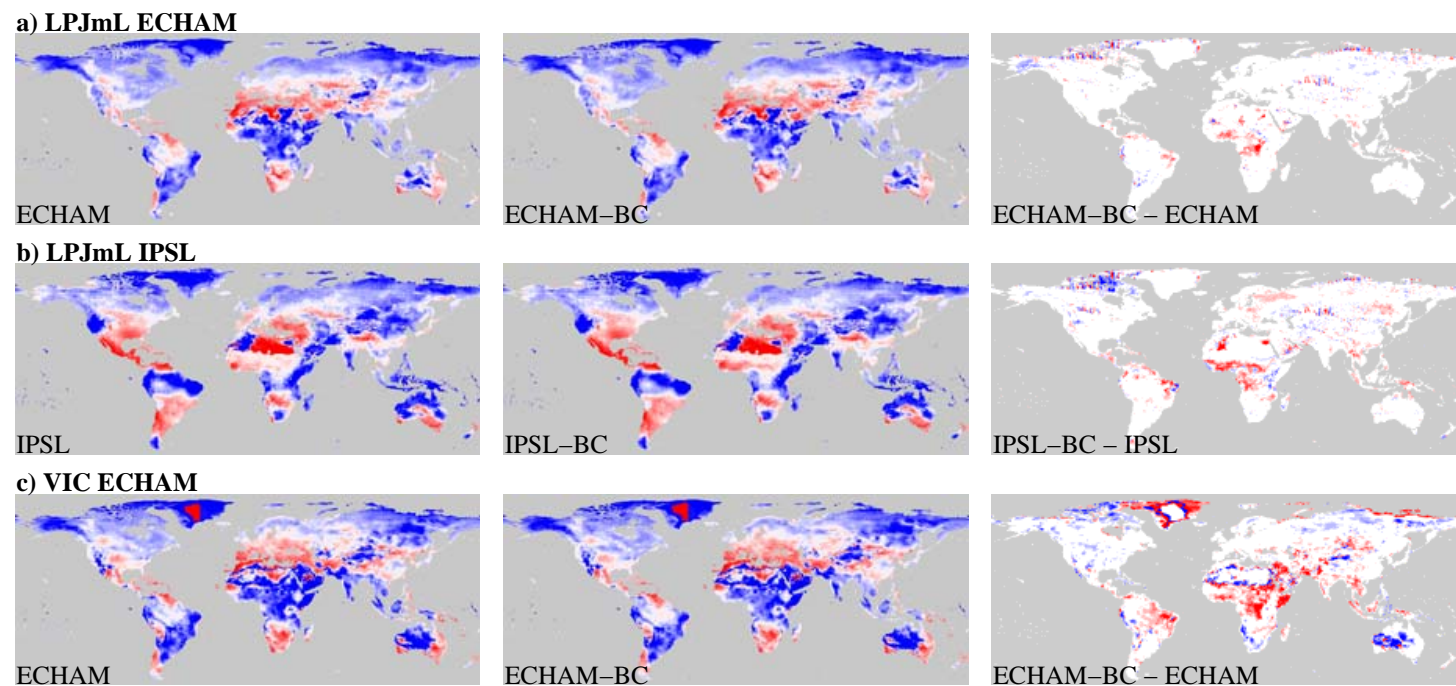

\section{d) VIC IPSL}
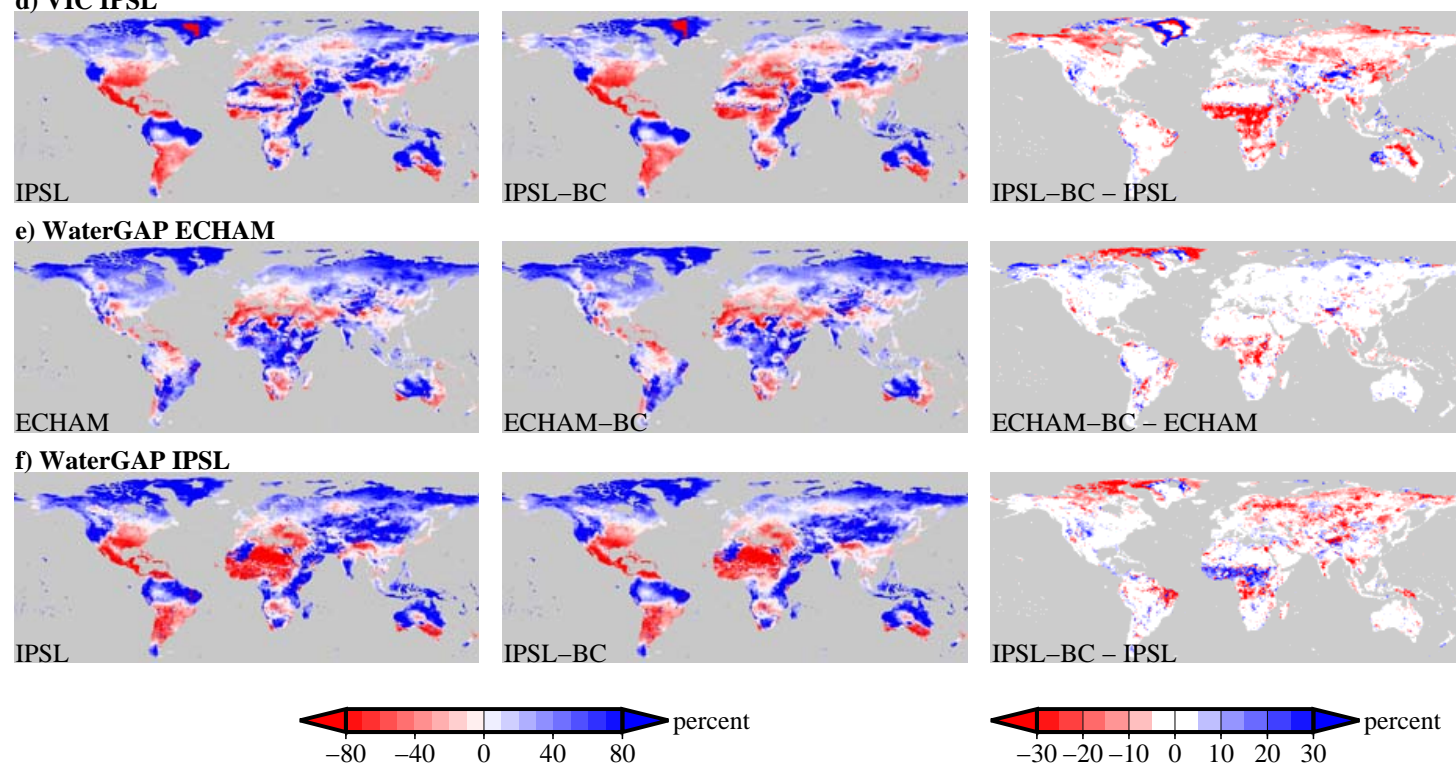

Fig. 8. Mean annual projected changes in simulated runoff; bias corrected results compared to original results. (a, b) LPJmL, (c, d) VIC, and (e, f) WaterGAP. BC denotes simulation results using bias corrected forcings. In the right panels, the areas where the differences in the relative runoff changes are both (1) significant at the 5 percent level and (2) more than 5 percentage points are shown.

2009). The projections of possible future changes are made over time scales of many decades and for which there are no precise past analogues (Randall et al., 2007), and the possible impacts are hence difficult to quantify. However, the assumption that the mean bias of the models does not change with time includes uncertainties that should be noted.

In this study, a simple bias correction method is implemented for radiation, humidity and wind values. The simple method does not ensure that spatio-temporal patterns and correlation between the variables are fully preserved, and was chosen despite the fact that precipitation and temperature in the climate forcing datasets used are bias corrected using a more sophisticated method (Piani et al., 2010). A more sophisticated bias correction method may yield more consistent meteorological fields, which subsequently may cause the hydrological simulations to match the baseline results even closer. In order to make more consistent meteorological fields, the cross correlation between the forcing variables (e.g. relationship between humidity and shortwave radiation) should also be taken into account in the bias correction procedure. This may well be favorable, and development of bias correction methods based on multiple meteorological fields concurrently is certainly a topic for further studies. On the other hand, the simple bias correction method implemented in this study results in good water flux matches when looking at the control period simulations. 
Table 2. Mean annual global terrestrial evapotranspiration $(\mathrm{ET})$ and runoff $(Q)$ numbers $\left(\mathrm{km}^{3} \mathrm{yr}^{-1}\right)$ for all model simulations included in this study. Original and bias corrected (BC) results for the control (1971-2000) and projection (2071-2100) periods.

\begin{tabular}{|c|c|c|c|c|c|c|c|c|c|c|}
\hline & \multicolumn{2}{|c|}{$\begin{array}{c}\text { WFD } \\
1971-2000\end{array}$} & \multicolumn{2}{|c|}{$\begin{array}{c}\text { ECHAM Cntrl } \\
1971-2000\end{array}$} & \multicolumn{2}{|c|}{$\begin{array}{l}\text { IPSL Cntrl } \\
1971-2000\end{array}$} & \multicolumn{2}{|c|}{$\begin{array}{c}\text { ECHAM A2 } \\
2071-2100\end{array}$} & \multicolumn{2}{|c|}{$\begin{array}{c}\text { IPSL A2 } \\
2071-2100\end{array}$} \\
\hline & ET & $Q$ & $\begin{array}{r}\mathrm{ET} \\
E T-B C\end{array}$ & $\begin{array}{r}Q \\
Q-B C\end{array}$ & $\begin{array}{r}\mathrm{ET} \\
E T-B C\end{array}$ & $\begin{array}{r}Q \\
Q-B C\end{array}$ & $\begin{array}{r}\mathrm{ET} \\
E T-B C\end{array}$ & $\begin{array}{r}Q \\
Q-B C\end{array}$ & $\begin{array}{r}\mathrm{ET} \\
E T-B C\end{array}$ & $\begin{array}{r}Q \\
Q-B C\end{array}$ \\
\hline LPJmL & 64787 & 62023 & $\begin{array}{l}66650 \\
63205\end{array}$ & $\begin{array}{l}60429 \\
63860\end{array}$ & $\begin{array}{l}75670 \\
64125\end{array}$ & $\begin{array}{l}52799 \\
63842\end{array}$ & $\begin{array}{l}68107 \\
65033\end{array}$ & $\begin{array}{l}70183 \\
73240\end{array}$ & $\begin{array}{l}78455 \\
66665\end{array}$ & $\begin{array}{l}64070 \\
75275\end{array}$ \\
\hline MPI-HM & 82270 & 44506 & 81881 & 45183 & 81612 & 46340 & 101004 & 42979 & 111602 & 41128 \\
\hline VIC & 71309 & 55774 & $\begin{array}{l}75838 \\
71793\end{array}$ & $\begin{array}{l}51592 \\
55622\end{array}$ & $\begin{array}{l}84417 \\
75900\end{array}$ & $\begin{array}{l}44051 \\
52455\end{array}$ & $\begin{array}{l}78591 \\
74804\end{array}$ & $\begin{array}{l}59908 \\
63711\end{array}$ & $\begin{array}{l}91049 \\
84418\end{array}$ & $\begin{array}{l}51182 \\
57798\end{array}$ \\
\hline WaterGAP & 73210 & 54720 & $\begin{array}{l}76085 \\
72266\end{array}$ & $\begin{array}{l}51685 \\
55465\end{array}$ & $\begin{array}{l}82427 \\
73147\end{array}$ & $\begin{array}{l}46203 \\
55458\end{array}$ & $\begin{array}{l}80061 \\
76514\end{array}$ & $\begin{array}{l}58719 \\
62242\end{array}$ & $\begin{array}{l}86694 \\
77094\end{array}$ & $\begin{array}{l}55640 \\
65239\end{array}$ \\
\hline
\end{tabular}

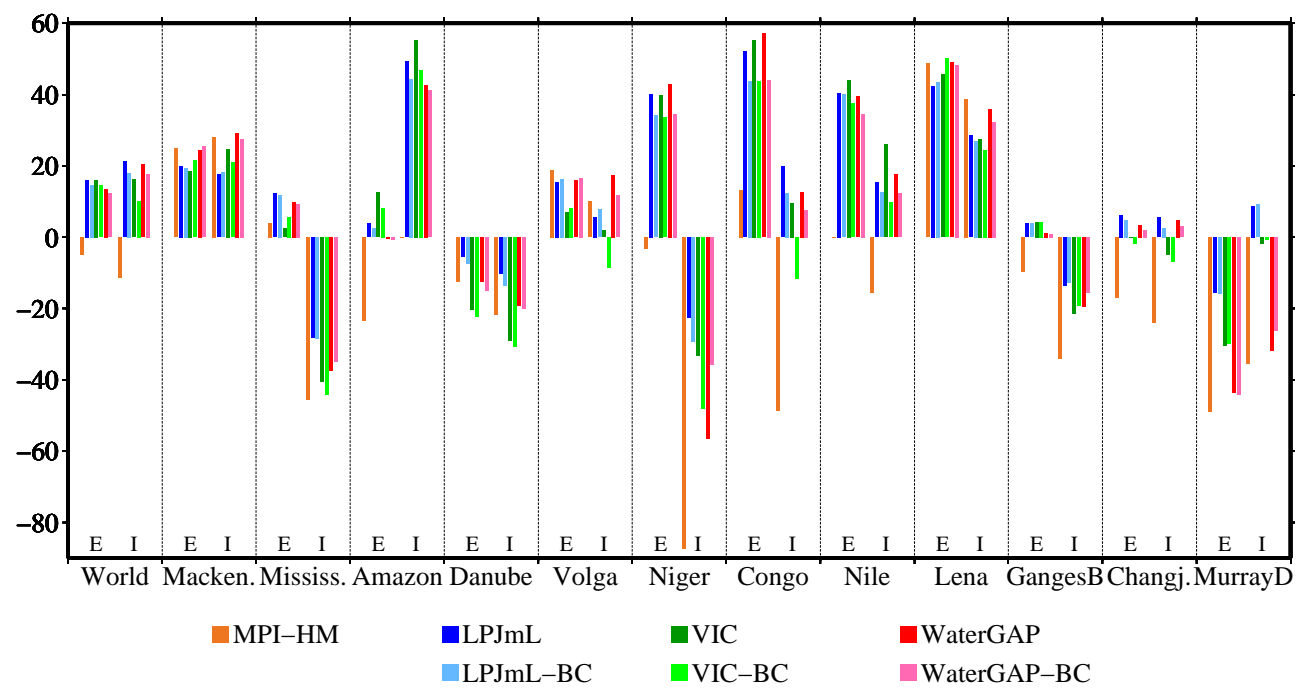

Fig. 9. Projected annual mean runoff changes (percent), with and without bias correction (BC) in 2071-2100 relative to 1971-2000 for the MPI-HM, LPJmL, VIC and WaterGAP models when using ECHAM (E) and IPSL (I) input datasets.

GCMs exhibit a number of significant systematic biases in their ability to simulate key features of the observed climate system (Randall et al., 2007). Despite the biases, IPCC concludes that there is still considerable confidence that climate models provide credible quantitative estimates of future climate changes (Randall, 2007). However, until GCMs perfectly reproduces current climate, GCM outputs cannot be used directly in hydrological impact studies without some form of bias correction. When GCM output is used uncorrected as input to hydrological simulations, the resulting amount and seasonal distribution of runoff may be far off from observations, see examples in this study, Wood et al. (2004) and Sharma et al. (2007). The weaknesses of bias correction methods should not be neglected, though, and Hagemann et al. (2011) noted three shortcomings in particu- lar: (1) the quality of observations limits the quality of bias correction, (2) it is assumed that the bias does not change with time, i.e. bias in the projection period is assumed similar to the bias in the control (historical) period for which the correction functions are developed, and (3) temporal errors cannot be corrected, e.g. if the climate model has a temporal error in the onset of the monsoon. Hagemann et al. (2011) also stated that the issue of climate model bias correction will be of interest for years to come, even though it is desirable that this will no longer be necessary in the long-term perspective. Whether the bias correction is adding or uncovering another level of uncertainty that is related to the uncertainty induced by the choice of the GCM, is a matter of scientific debate. The latter seems to apply in cases where biases lead to positive regional feedbacks to the climate change signal. 

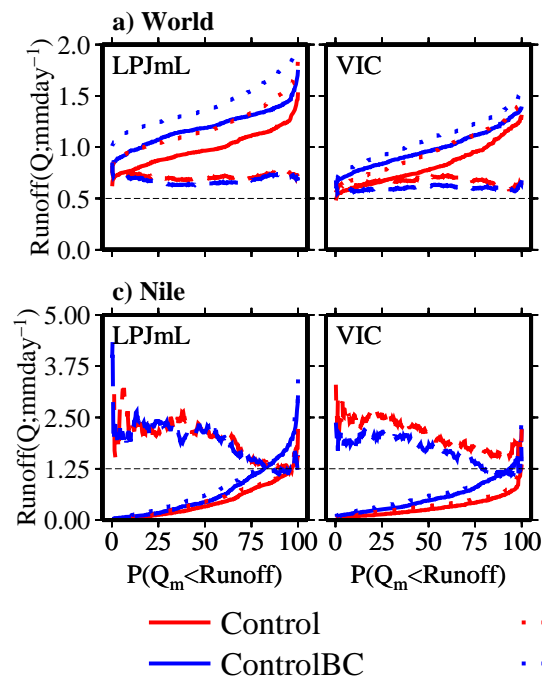
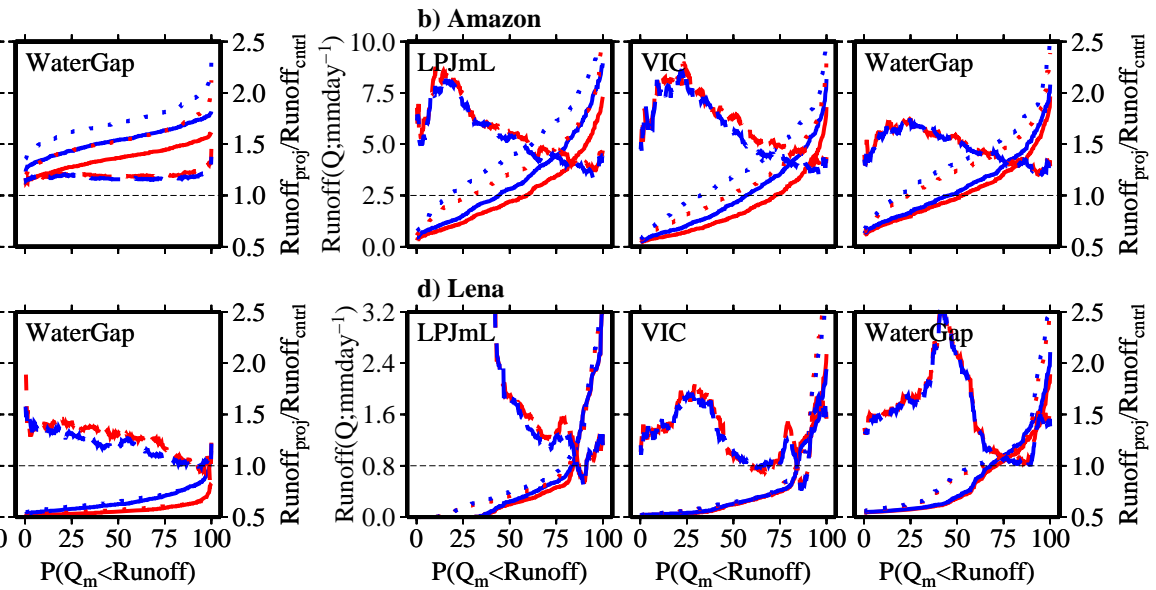

-...Projection

... ProjectionBC d) Lena

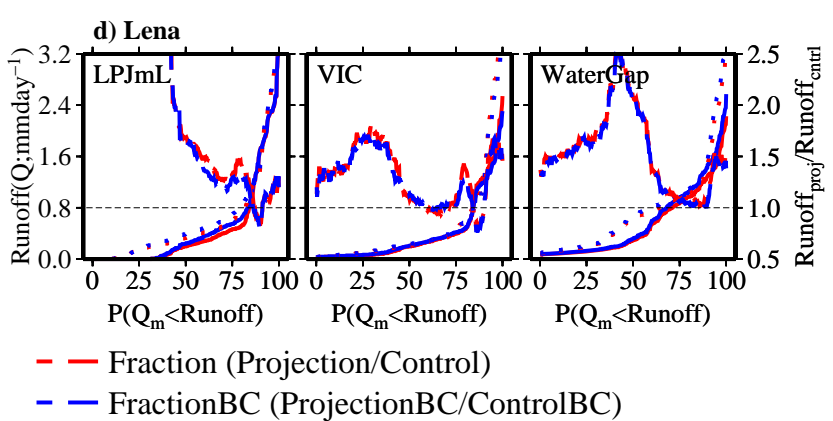

Fig. 10. World and basin cumulative distribution functions of monthly simulated runoff $\left(Q_{\mathrm{m}}\right)$ when using IPSL input data, 1971-2000 (control period) and 2071-2100 (projection period), with and without bias correction (BC). Included is also a comparison of the projection period results to the control period results (right y-axis).

This, for example, may be the case in regions with strong land-atmosphere coupling where the coupling strength will change under future climate conditions, as pointed out by Seneviratne et al. (2006) and van den Hurk et al. (2005). Hagemann et al. (2011) noted that the bias correction of $P$ and $T$ identified, but not necessarily caused, this extra level of uncertainty. How to handle and possibly reduce this uncertainty is an important question in climate change impact research, and should be subject to future investigations whose outcomes have to be communicated to the users of research results.

\section{Conclusions}

This study demonstrates that radiation, humidity and wind speed values have potentially large effects on simulated water fluxes, and that using these values directly from climate models can result in very different evapotranspiration and runoff estimates than when using values based on reanalysis and observational data. The differences are relatively largest in energy limited areas where estimated incoming radiation deviates much. The study also shows that after introducing a simple bias correction procedure on radiation, humidity and wind speed values, the simulated water fluxes are much closer to the baseline results.

Projected relative changes in mean annual runoff (20712100 compared to 1971-2000) are fairly similar using original and bias corrected forcings (radiation, humidity and wind speed). Hence, introducing a bias correction may not change relative hydrologic projections much. Sub-annual relative differences are somewhat larger, but only in a few areas has it been shown that the bias correction causes significant alterations in the relative projections. However, as for the control period, the absolute values of simulated runoff and evapotranspiration are very different before and after introducing the bias correction. These differences are seen at all ranges of the simulated runoff distributions, and hence may influence e.g. water scarcity analyses considerably. When comparing the findings of this study to other studies, it can be concluded that bias correction of radiation, humidity and wind affect hydrologic projections less than bias correction of precipitation and temperature.

Acknowledgements. This research was undertaken as part of the European Union (FP6) funded Integrated Project called WATCH (contract 036946). The comments and suggestions of Uwe Ehret, two anonymous reviewers and the editor are greatly appreciated.

Edited by: S. Schymanski

\section{References}

Alcamo, J., Döll, P., Henrichs, T., Kaspar, F., Lehner, B., Rösch, T., and Siebert, S.: Development and testing of the WaterGAP 2 global model of water use and availability, Hydrol. Sci. J., 48, 317-333, 2003.

Bates, B. C., Kundzewicz, Z. W., Wu, S., and Palutikof, J. P. (Eds.): Climate Change and Water. Technical Paper of the Intergovernmental Panel on Climate Change, IPCC Secretariat, Geneva, 210 pp., 2008.

Bondeau, A., Smith, P., Zaehle, S., Schaphoff, S., Lucht, W., Cramer, W., Gerten, D., Lotze-Campen, H., Müller, C., Reichstein, M., and Smith, B.: Modelling the role of agriculture for the 20th century global terrestrial carbon balance, Global Change Biol. 13, 679-706, 2007.

Haddeland, I., Clark, D. B., Franssen, W., Ludwig, F., Voß, F., Arnell, N. W., Bertrand, N., Best, M., Folwell, S., Gerten, D., 
Gomes, S., Gosling, S. N., Hagemann, S., Hanasaki, N., Harding, R., Heinke, J., Kabat, P., Koirala, S., Oki, T., Polcher, J., Stacke, T., Viterbo, P., Weedon, G. P., and Yeh, P.: Multimodel Estimate of the Global Terrestrial Water Balance: Setup and First Results, J. Hydrometeor., 12, 869-884, doi:10.1175/2011JHM1324.1, 2011.

Hagemann, S. and Dümenil Gates, L.: Improving a subgrid runoff parameterization scheme for climate models by the use of high resolution data derived from satellite observations, Clim. Dynam., 21, 349-359, 2003.

Hagemann, S. and Dümenil, L.: A parameterization of the lateral waterflow for the global scale, Clim. Dynam., 14, 17-31, 1998.

Hagemann, S., Chen, C., Haerter, J. O., Heinke, J., Gerten, D., and Piani, C.: Impact of a statistical bias correction on the projected hydrological changes obtained from three GCMs and two hydrology models, J. Hydrometeorol., 12, 556-578, doi:10.1175/2011JHM1336.1, 2011.

Harding, R. J., Best, M., Blyth, E., Hagemann, S., Kabat, P., Tallaksen, L. M., Warnaars, T., Wiberg, D., Weedon, G. P., van Lanen, H., Ludwig, F., and Haddeland, I.: Preface to the "Water and Global Change (WATCH)" special collection: Current knowledge of the terrestrial Global Water Cycle, J. Hydrometeorol. 12, 1149-1156, doi:10.1175/JHM-D-11-024.1, 2011.

Hay, L. E., Wilby, R. L., and Leavesley, G. H.: A comparison of delta change and downscaled GCM scenarios for three mountainous basins in the United States, J. Am. Water Resour. Assoc., 36, 387-398, 2000.

Kim, J.: A nested modeling study of elevation-dependent climate change signals in California induced by increased atmospheric $\mathrm{CO}_{2}$, Geophys. Res. Lett. 28, 2951-2954, 2001.

Liang, X., Lettennmaier, D. P., Wood, E. F., and Burges, S. J.: A simple hydrologically based model of land surface water and energy fluxes for general circulation models, J. Geophys. Res., 99, 14415-14428, 1994.

Materia, S., Dirmeyer, P. A., Guo, Z., Alessandri, A., and Navarra, A.: The sensitivity of simulated river discharge to land surface representation and meteorological forcings, J. Hydrometeor., 11, 334-351, doi:10.1175/2009JHM1162.1, 2010.

Meehl, G. A., Stocker, T. F., Collins, W. D., Friedlingstein, P., Gaye, A. T., Gregory, J. M., Kitoh, A., Knutti, R., Murphy, J. M., Noda, A., Raper, S. C. B., Watterson, I. G., Weaver, A. J., and Zhao, Z.-C.: Global Climate Projections, in: Climate Change 2007: The Physical Science Basis. Contribution of Working Group I to the Fourth Assessment Report of the Intergovernmental Panel on Climate Change, edited by: Solomon, S., Qin, D., Manning, M., Chen, Z., Marquis, M., Averyt, K. B., Tignor, M., and Miller, H. L., Cambridge University Press, Cambridge, United Kingdom and New York, NY, USA, 2007.

Nasonova, O. N., Gusev Y. M., and Kovalev Y. E.: Impact of uncertainties in meteorological forcing data and land surface parameters on global estimates of terrestrial water balance components, Hydrol. Process., 25, 1074-1090, 2011.

Piani, C., Weedon, G. P., Best, M., Gomes, S. M., Viterbo, P., Hagemann, S., and Haerter, J. O.: Statistical bias correction of global simulated daily precipitation and temperature for the application of hydrological models, J. Hydrol., 395, 199-215, doi:10.1016/j.jhydrol.2010.10.024, 2010.

Randall, D. A., Wood, R. A., Bony, S., Colman, R., Fichefet, T., Fyfe, J., Kattsov, V., Pitman, A., Shukla, J., Srinivasan, J., Stouf- fer, R. J., Sumi A., and Taylor, K. E.: Climate Models and Their Evaluation, in: Climate Change 2007: The Physical Science Basis. Contribution of Working Group I to the Fourth Assessment Report of the Intergovernmental Panel on Climate Change, edited by: Solomon, S., Qin, D., Manning, M., Chen, Z., Marquis, M., Averyt, K. B., Tignor, M., and Miller, H. L., Cambridge University Press, Cambridge, United Kingdom and New York, NY, USA, 589-662, 2007.

Rost, S., Gerten, D., Bondeau, A., Lucht, W., Rohwer, J., and Schaphoff, S.: Agricultural green and blue water consumption and its influence on the global water system, Water Resour. Res., 44, W09405, doi:10.1029/2007WR006331, 2008.

Seneviratne, S. I., Lüthi, D., Litschi, M., and Schär, C.: Landatmosphere coupling and climate change in Europe, Nature, 443, 205-209, 2006.

Sharma, D., Das Gupta, A., and Babel, M. S.: Spatial disaggregation of bias-corrected GCM precipitation for improved hydrologic simulation: Ping River Basin, Thailand, Hydrol. Earth Syst. Sci., 11, 1373-1390, doi:10.5194/hess-11-1373-2007, 2007.

Shi, X. G., Wild, M., and Lettenmaier, D. P.: Surface radiative fluxes over the span-Arctic land region: Variability and trends, J. Geophys. Res., 115, D22104, doi:10.1029/2010JD014402, 2010.

Sperna Weiland, F. C., van Beek, L. P. H., Kwadijk, J. C. J., and Bierkens, M. F. P.: The ability of a GCM-forced hydrological model to reproduce global discharge variability, Hydrol. Earth Syst. Sci., 14, 1595-1621, doi:10.5194/hess-14-15952010, 2010.

Storelvmo, T., Lohmann, U., and Bennartz, R.: What governs the spread in shortwave forcings in the transient IPCC AR4 models?, Geophys. Res. Lett., 36, L01806, doi:10.1029/2008GL036069, 2009.

Themeß1, M. J., Gobiet, A., and Leuprecht, A.: Empirical-statistical downscaling and error correction of daily precipitation from regional climate models, Int. J. Climatol., 31, 1530-1544, doi:10.1002/joc.2168, 2010.

van den Hurk, B., Hirschi, M, Schär, C., Lenderink, G., van Meijgaard, E., van Ulden, A., Rockel, B., Hagemann, S., Graham, P., Kjellstrom, E., and Jones, R.: Soil control on runoff response to climate change in regional climate model simulations, J. Climate, 18, 3536-3551, 2005.

Waszkewitz, J., Lenzen, P., and Gillet, N.: The PINGO package (Procedural INterface for Grib formatted Objects), DKRZ Technical Rep. 11, Hamburg, Germany (available at: http://www.mad. zmaw.de/Pingo/downloads.html), 1996.

Weedon, G. P., Gomes, S., Viterbo, P., Shuttleworth, J., Blyth, E., Österle, H., Adam, J. C., Bellouin, N., Boucher, O., and Best, M.: Creation of the WATCH Forcing Data and its use to assess global and regional reference crop evaporation over land during the twentieth century, J. Hydrometeorol., 12, 823-848, doi:10.1175/2011JHM1369.1, 2011.

Wild, M. and Liepert, B.: The Earth radiation balance as driver of the global hydrological cycle, Env. Res. Lett., 5, 025003, doi:10.1088/1748-9326/5/2/025203, 2010.

Wood, A. W., Leung, L. R., Shridhar, V., and Lettenmaier, D. P.: Hydrologic implications of dynamical and statistical approaches to downscaling climate outputs, Climatic Change, 62, 189-216, 2004. 